University of Wollongong

Research Online

Faculty of Engineering and Information

Faculty of Engineering and Information

Sciences - Papers: Part A

Sciences

$1-1-2014$

\title{
Effects of chemical preservation on flux and solute rejection by reverse osmosis membranes
}

Kha L. Tu

University of Wollongong, Ikt883@uowmail.edu.au

Allan Chivas

University of Wollongong, toschi@uow.edu.au

Long D. Nghiem

University of Wollongong, longn@uow.edu.au

Follow this and additional works at: https://ro.uow.edu.au/eispapers

Part of the Engineering Commons, and the Science and Technology Studies Commons

Research Online is the open access institutional repository for the University of Wollongong. For further information contact the UOW Library: research-pubs@uow.edu.au 


\title{
Effects of chemical preservation on flux and solute rejection by reverse osmosis membranes
}

\begin{abstract}
This study investigates the impacts of chemical preservation on the performance of polyamide reverse osmosis membranes with respect to water permeability and solute rejection. Three preservative chemicals, namely formaldehyde, sodium metabisulfite, and 2,2-Dibromo-3-Nitrilopropionamide, were evaluated for membrane preservation at $\mathrm{pH} 3$ and 7. Experimental data show that chemical preservation may change the membrane surface properties, and consequently water permeability and solute rejection efficiency of the membrane are negatively impacted. The impacts of preservation on boron rejection and sodium rejection are similar in magnitude and more significant than those on water permeability. The results indicate that the impact of chemical preservation on the membrane depends on both the preserving chemicals used and the solution $\mathrm{pH}$ value. More importantly, the undesirable impacts of chemical preservation can be minimised by appropriate selection of the preservatives and by preserving the membrane in a reducing condition. A near-neutral $\mathrm{pH}$ (i.e., $\mathrm{pH} 7$ ) is necessary to avoid any significant negative impacts on membrane performance due to chemical preservation using either formaldehyde or sodium metabisulfite. Results reported here suggest that the previously recommended minimum $\mathrm{pH}$ value of 3 of the preservative solution may be inadequate.
\end{abstract}

\section{Keywords}

membranes, chemical, preservation, flux, effects, solute, rejection, osmosis, reverse

Disciplines

Engineering | Science and Technology Studies

\section{Publication Details}

Tu, K. L., Chivas, A. R. \& Nghiem, L. D. (2014). Effects of chemical preservation on flux and solute rejection by reverse osmosis membranes. Journal of Membrane Science, 472 202-209. 


\title{
Effects of chemical preservation on flux and solute rejection by reverse osmosis membranes
}

\author{
Revised manuscript submitted to \\ Journal of Membrane Science
}

Aug 2014

${ }^{1}$ Strategic Water Infrastructure Laboratory and GeoQuEST Research Centre, School of Civil, Mining and Environmental Engineering University of Wollongong, NSW 2522, Australia

${ }^{2}$ GeoQuEST Research Centre, School of Earth and Environmental Sciences, University of Wollongong, NSW 2522, Australia

\footnotetext{
* Corresponding author: Long Duc Nghiem, Email: longn@uow.edu.au, Ph +61 242214590
} 


\begin{abstract}
This study investigates the impacts of chemical preservation on the performance of polyamide reverse osmosis membranes with respect to water permeability and solute rejection. Three preservative chemicals, namely formaldehyde, sodium metabisulfite, and 2,2-Dibromo-3Nitrilopropionamide, were evaluated for membrane preservation at $\mathrm{pH} 3$ and 7. Experimental data show that chemical preservation may change the membrane surface properties, and consequently water permeability and solute rejection efficiency of the membrane are negatively impacted. The impacts of preservation on boron rejection and sodium rejection are similar in magnitude and more significant than those on water permeability. The results indicate that the impact of chemical preservation on the membrane depends on both the preserving chemicals used and the solution $\mathrm{pH}$ value. More importantly, the undesirable impacts of chemical preservation can be minimised by appropriate selection of the preservatives and by preserving the membrane in a reducing condition. A near-neutral $\mathrm{pH}$ (i.e., $\mathrm{pH} 7$ ) is necessary to avoid any significantly negative impacts on membrane performance due to chemical preservation using either formaldehyde or sodium metabisulfite. Results reported here suggest that the previously recommended minimum $\mathrm{pH}$ value of 3 of the preservative solution may be inadequate.
\end{abstract}

Keywords: chemical preservation, reverse osmosis (RO), formaldehyde, sodium metabisulfite (SMBS), boron, redox potential. 


\section{Introduction}

In recent years, the demand for clean water has substantially increased due to improved living standards and continuing population growth. At the same time, extreme weather patterns and the uneven distribution of freshwater resources across the globe have further intensified the issue of fresh water scarcity. As a result, a major challenge of our time is to reliably provide adequate clean water for municipal use as well as industrial and agricultural production [1]. This challenge has been progressively addressed by the development of new technologies to purify alternative water resources such as seawater, brackish water, and reclaimed wastewater for various beneficial uses [1, 2]. Amongst these technologies, reverse osmosis (RO) has been possibly the most widely used technology for seawater desalination and water recycling [3]. In fact, RO membranes account for about half of the current worldwide desalination capacity [4-6]. Since 2003, in Australia, more than 30 new RO plants have been constructed and commissioned for either seawater desalination or water recycling $[7,8]$. In addition, the widespread use of small-to medium-scale RO systems has been seen for brackish water desalination for mine sites [9], remote communities [10], military outposts [11] and a range of industrial applications such as coal seam gas produced water treatment, cooling water demineralisation [12], and wine-making [13].

Although RO membranes are designed for continuous operation, many small scale RO systems are operated on an intermittent basis to match the variations in the supply source and production demand. Some large-scale RO seawater desalination and water recycling plants that are located in regions with extreme climate variability can also be subjected to demand variation. For example, in Australia where the climatic pattern is characterised by intense droughts and flooding rains, several large-scale RO desalination plants, which were built to ensure a secured freshwater supply, have been recently mothballed for energy conservation. This is because seawater desalination is more expensive and energy intensive than the filtration of surface water, which has become abundant during the last few very wet years [14].

The widespread and diversified applications of RO have presented a new challenge to membrane technologists and practitioners. Once the RO plant operation is suspended for more than 48 hours, the membrane must be preserved in a chemical solution to prevent biological growth and material degradation [15]. Despite the need to operate small-scale RO systems on an intermittent 
basis and to occasionally mothball large-scale RO plants, there has been very little research work on membrane preservation. The literature review undertaken as part of this study revealed that there has been only one report [16] on this topic in the peer review literature.

Most membrane manufacturers provide only a brief guideline for chemical preservation. Sodium metabisulfite (SMBS) at $0.05-1.5 \%$ (wt/wt) is currently the most widely used preservative chemical for RO membranes [15]. Formaldehyde solution at $0.1-1 \%(\mathrm{wt} / \mathrm{wt})$ has also been recommended as an alternative preservative solution due to its biocide property. However, because of its toxicity, the application of formaldehyde for membrane preservation is less common compared to SMBS [17]. In addition to SMBS and formaldehyde, in 2013, Hydranautics released a Technical Service Bulletin (TSB 110.11) considering the use of several other biocides including 2,2-Dibromo-3-nitrilopropionamide (DBNPA) and isothiazolin for chemical preservation [17]. Some commercially available pre-mixed solutions (Applied Membranes AM88, Applied Membranes AM225, PermaClean PC-55, PermaClean PC-56) have also been designed for RO membrane preservation although their exact ingredients are the proprietary information of the manufacturers. During membrane preservation, SMBS and formaldehyde can be oxidised resulting in a decrease in the preservative solution $\mathrm{pH}$. Thus, several membrane manufacturers have specified that the $\mathrm{pH}$ of preservative solutions be regularly monitored and maintained at $\mathrm{pH} 3$ or higher [15].

This study aims to investigate the impacts of chemical preservation of RO membranes on water permeability and solute rejection. In addition to conductivity and sodium, boron is also selected as a model solute since it is a solute of significant concern in many seawater and brackish water desalination applications [18-20]. Boron is a ubiquitous element existing in natural water and wastewater in the form of boric acid. Average boron concentration in seawater is approximately $4.6 \mathrm{mgL}^{-1}$ which is known to be over the tolerance level of many important agricultural plants such as citrus and blackberry [21]. Boron rejection by RO membranes is considerably lower than that of $\mathrm{NaCl}[21,22]$. Previous research has shown that changes in operating conditions such as membrane fouling could exert significant impact on the rejection of boron by RO membranes $[23,24]$. 


\section{Experimental}

\subsection{Membranes and chemicals}

A low-pressure and a high-pressure RO membrane - namely ESPA2 and SWC5 - from Hydranautics (Oceanside, CA, USA) were used. The ESPA2 membrane is used for water reclamation or in the second pass of a seawater desalination plant for boron removal. The SWC5 membrane is commonly used for seawater desalination. According to the manufacturer, these are thin-film composite membranes consisting of an ultra-thin polyamide (or polyamide derivative) skin layer on a micro-porous support layer.

Analytical grade SMBS (Chem-Supply, SA, Australia), formaldehyde (BDH Prolabo, VWR, QLD, Australia) and DBNPA (Sigma-Aldrich, MO, USA) were used as membrane preservative chemicals. Analytical grade $\mathrm{NaCl}, \mathrm{CaCl}_{2}, \mathrm{NaHCO}_{3}$, and $\mathrm{B}(\mathrm{OH})_{3}$ (Ajax Finechem, Taren Point, $\mathrm{NSW}$, Australia) were used to prepare the feed solution. Suprapur $\mathrm{HNO}_{3}$ (Merck Co., Darmstadt, Germany) was used for sample dilution prior to analysis. Milli-Q water (Millipore, Billerica, MA, USA) was used for the preparation of all stock and feed solutions.

\subsection{Cross-flow membrane filtration system}

A bench-scale cross-flow membrane filtration system (Supplementary Data, Figure S1) was utilised for testing the membrane performance. A detailed description of this system is available elsewhere [22]. The membrane cell has an active surface area of $40 \mathrm{~cm}^{2}(10 \mathrm{~cm} \times 4 \mathrm{~cm})$ with a channel height of $2 \mathrm{~mm}$.

At the beginning of each experiment, the membrane sample was compacted by using Milli-Q water at 30 bar for $18 \mathrm{~h}$. A stable flux was usually obtained within the first $10 \mathrm{~h}$ run. Following the membrane compaction, pure water permeability of the membrane was measured at 5, 10, 15, 20,25 , and $30 \mathrm{bar}\left(\right.$ at $20^{\circ} \mathrm{C}$ ). Electrolyte solution was then added to the feed reservoir making up a $10 \mathrm{~L}$ feed water containing $10 \mathrm{mM} \mathrm{NaCl}, 1 \mathrm{mM} \mathrm{CaCl}_{2}, 1 \mathrm{mM} \mathrm{NaHCO}_{3}$, and $0.43 \mathrm{mM} \mathrm{B}(\mathrm{OH})_{3}$ (or $4.6 \mathrm{mgL}^{-1} \mathrm{~B}$ ). Boron and sodium rejections were obtained at permeate fluxes of 10, 20, 42, 60 $\mathrm{Lm}^{-2} \mathrm{~h}^{-1}(\mathrm{LMH})$, temperatures of $10,20,30,40{ }^{\circ} \mathrm{C}$, cross-flow velocity of $42 \mathrm{~cm} \cdot \mathrm{s}^{-1}$, and $\mathrm{pH}$ values of $7,8,9,11$. The permeate flux and the cross-flow velocity were controlled by adjusting the bypass valve and the back-pressure regulator. The applied pressure was linearly proportional 
to permeate flux, reversely proportional to temperature and independent to the feedwater $\mathrm{pH}$ (Supplementary Data, Figure S3). Unless otherwise stated, the standard testing condition is 20 LMH flux, $20{ }^{\circ} \mathrm{C}, \mathrm{pH} 8$, and cross-flow velocity of $42 \mathrm{~cm} \cdot \mathrm{s}^{-1}$ (i.e. retentate flow of $120 \mathrm{~L} . \mathrm{h}^{-1}$ ). The $\mathrm{pH}$ value was adjusted using either $1 \mathrm{M} \mathrm{NaOH}$ or $1 \mathrm{M} \mathrm{HCl}$ solution. In all experiments, once the target operational parameters had been obtained, the system was stabilised for 60 min before feed and permeate samples of $20 \mathrm{~mL}$ each were taken for analysis.

\subsection{Membrane preservation protocol}

A virgin membrane sample was first evaluated for pure water permeability and salt rejection. The sample was then removed from the membrane cell for preservation. Membrane preservation was simulated by submerging a membrane sample in the preservative solution in a $600 \mathrm{~mL}$ airtight glass bottle for 14 days. SMBS and formaldehyde preservative solutions were prepared at a strength of 5\% (wt/wt) in Milli-Q water and were adjusted to either $\mathrm{pH} 3$ or 7 . These conditions represent a chemical preservation period from 2 months to up to 2 years. DBNPA preservative solution was prepared at a strength of $1 \%(\mathrm{wt} / \mathrm{wt})$ in Milli-Q water and was adjusted to $\mathrm{pH} 7$. The bottle was completely filled with the preservative solution to eliminate any head space and was placed in the dark. The $\mathrm{pH}$ of the preserving solution was monitored during the preservation period. At the end of the simulated preservation period, the preserved membrane samples were rinsed with copious amounts of Milli-Q water and then evaluated again for water permeability and salt rejection.

It is noted that the permeate flux of different elements of the same membrane name may vary up to $20 \%$ due to variation in the manufacturing process [25]. In fact, by testing seven $10 \mathrm{~cm} \times 4 \mathrm{~cm}$ membrane samples, variations of $9 \%$ and $17 \%$ in water permeability of the ESPA2 and SWC5 membrane, respectively, were observed in this study. On the other hand, the mounting and dismounting of the membrane sample to the RO cell did not result in any discernible variation in permeate flux and salt rejection as can be seen from three repeated cycles of filtration after sample mounting and dismounting (Supplementary Data, Figure S2). By using a single membrane sample for evaluating permeate flux and salt rejection before and after preservation, the impact of individual preservative chemicals on the membrane can be accurately examined. However, it is noteworthy that inconsistency among different membrane samples used for

different preserving chemicals may still occur. In addition, this study used virgin membranes for 
the investigation. In practice, chemical preservation would be applied to used membranes, which have been exposed to various chemicals (e.g. cleaning and disinfection agents) and thus their surface properties and separation performance may differ from those under virgin condition [26, 27]. As such, changes in the performance of the used membrane due to preservation may be quantitatively different to this study. Similarly, the occurrence of foulants such as colloidal particles and organic matter on the membrane surface may also influence the impact of preserving chemicals.

\subsection{Membrane characterisation methods}

The electro-kinetic property of the membranes was measured using a SurPASS streaming potential analyser (Anton Paar GmbH, Graz, Austria). The zeta potential of membrane surface was calculated from the measured streaming potential using the Fairbrother-Mastin approach [28]. All streaming potential measurements were conducted in a background electrolyte solution containing $1 \mathrm{mM} \mathrm{KCl}$, at 500 mbar streaming pressure, and room temperature of approximately $25{ }^{\circ} \mathrm{C}$. Analytical grade $\mathrm{HCl}$ and $\mathrm{KOH}$ were used to adjust the $\mathrm{pH}$ by means of automatic titration.

The hydrophobicity of the membrane surface was measured using a Rame-Hart goniometer (Model 250, Rame-Hart, Netcong, NJ) following the standard sessile drop method. Prior to each measurement, the membrane sample was dried in air for approximately $5 \mathrm{~h}$. Five Milli-Q water droplets were applied to each membrane sample and the contact angle was immediately measured on both sides of the droplet. Measurements were conducted at room temperature (approximately $25^{\circ} \mathrm{C}$ ).

Attenuated Total Reflection - Fourier Transform Infrared Spectroscopy (ATR-FTIR) analysis was conducted using a Shimadzu IRAffinity-1 (Kyoto, Japan) spectrometer to determine major functional groups of the virgin and preserved membranes. Membrane samples were placed on the ATR crystal and pressed onto the surface with a plate press. The measured spectrum was between $600 \mathrm{~cm}^{-1}$ and $1750 \mathrm{~cm}^{-1}$ at a resolution of $2 \mathrm{~cm}^{-1}$. Each scan was performed 20 times. Background correction was performed at the beginning of each measuring batch. 


\subsection{Analytical methods}

The concentrations of boron and sodium were analysed using an Agilent $7500 \mathrm{cs}$ inductivelycoupled plasma mass spectrometry (ICP-MS) system (Agilent Technologies, Wilmington, DE, USA). Concentrations of the ${ }^{11} \mathrm{~B}$ and ${ }^{23} \mathrm{Na}$ isotope were acquired and reported as the overall concentrations of boron and sodium. Detection limits for ${ }^{11} \mathrm{~B}$ and ${ }^{23} \mathrm{Na}$ were approximately 50 and $140 \mathrm{ngL}^{-1}$, respectively. Samples of the feedwater and permeate were diluted respectively 400 and 200 times using a 2\% Suprapur $\mathrm{HNO}_{3}$ solution. Calibration and sensitivity tuning were conducted at the beginning of every analysis batch. Internal calibration was done using a Merck ICP multi-element standard solution. The coefficient of determination $\left(\mathrm{R}^{2}\right)$ for calibrations was greater than 0.99 . The tuning was done using a multi-element tuning solution that contains 1 $\mu \mathrm{gL}^{-1}$ of lithium, yttrium, cerium, thallium and cobalt. Each analysis was conducted in triplicate and the variation was found less than 5\%. Any instrumental drift during the analysis was corrected by analysing a $5 \mu \mathrm{gL}^{-1}$ calibration standard every five samples.

Conductivity and $\mathrm{pH}$ were measured using an Orion 4-Star Plus $\mathrm{pH} /$ conductivity meter (Thermo Fisher Scientific, Beverly, MA). Redox potential was measured by an ORP meter model TPS WP-80D (Thermo Fisher Scientific).

The rejection of solutes and changes in membrane performance were calculated using the following equations:

$\operatorname{Rej}(\%)=\frac{C_{f}-C_{p}}{C_{f}} \times 100$

Where $\mathrm{C}_{\mathrm{f}}$ and $\mathrm{C}_{\mathrm{p}}$ are the concentrations of solute in feedwater and permeate, respectively.

Change $(\%)=\frac{X_{\text {pres }}-X_{\text {vir }}}{X_{\text {vir }}} \times 100$

Where $X_{\text {pres }}$ and $X_{\text {vir }}$ are the performances (rejection or flux) of the preserved membrane and the virgin membrane, respectively. 


\section{Results and discussion}

\subsection{Changes in the membrane surface properties}

\subsubsection{Charge density}

As the solution $\mathrm{pH}$ increases from 3 to 11 , the membrane surface charge changed from slightly positive to negative (Figure 1). This is a well-known phenomenon and is attributed to the deprotonation of the carboxylic and amine groups in polyamide active layer at increasing $\mathrm{pH}$ [29]. Furthermore, results reported here also show that the membrane surface charge can be significantly altered after chemical preservation (Figure 1). Changes in the membrane surface charge appeared to be driven by both the solution $\mathrm{pH}$ and the preserving chemicals. After being exposed to a $\mathrm{pH} 7$ solution (without any preservative chemicals) for 14 days, the zeta potential profiles of both the ESPA2 and SWC5 were identical to those under the virgin condition. In contrast, before and after 14 days of exposure to a $\mathrm{pH} 3$ solution (without any preservative chemicals), when measured at $\mathrm{pH} 8$, the zeta potentials of the ESPA2 and SWC5 changed from 45 to $-23 \mathrm{mV}$ and -50 to $-14 \mathrm{mV}$, respectively. Changes in the membrane surface charge after exposure to the preservative chemicals used in this study could also be observed. In general, the membrane became less negatively charged in comparison to the virgin condition. However, there seems to be a combined effect of the solution $\mathrm{pH}$ and preservative chemical on the membrane surface charge. After 14 days of exposure to a $\mathrm{pH} 3$ solution that did not contain any preservative chemicals, the most significant decrease in the membrane negative surface charge (when measured at $\mathrm{pH}$ 7-8) could be observed with both the ESPA2 and SWC5. On the other hand, both the ESPA2 and SWC5 were less negatively charged after 14 days of exposure to preservative solution (which was maintained at $\mathrm{pH} 7$ ). Changes in the membrane surface charge due to chemical preservation reported here may influence the rejection of ionic (or charged) solutes. More importantly, these changes imply that there could be chemical and/or physical transformation of the membrane active skin layer in response to chemical preservation. Changes in the membrane charged profile may indicate an absorption of free ions on the membrane surface [29], or even a cleavage of functional groups within the membrane structure such as carboxylic and amine groups [30]. The charge profile of the SWC5 membrane appeared to be more affected by the chemical preservation than that of the ESPA2 membrane, probably because the SWC5 has a greater charge density (Figure 1) which encourages the absorption of counter- 
ions on the membrane surface. It is noteworthy that the measured zeta potential values could be affected by the membrane surface roughness, in which lower zeta potential values would be obtained as the surface roughness increased [31].

\section{[Figure 1]}

\subsubsection{Hydrophobicity}

The contact angles of the virgin ESPA2 and SWC5 membranes were $55^{\circ}$ and $50^{\circ}$, respectively. In all cases, the membrane contact angle decreased and the membrane became less hydrophobic after chemical preservation. The decrease in the membrane hydrophobicity was more severe when the preservative chemical solution was maintained at $\mathrm{pH} 3$ compared to $\mathrm{pH}$ 7. In addition, the effect of chemical preservation on the membrane surface hydrophobicity decreased in the order formaldehyde, SMBS, and DBNPA. These observations were consistent for both the ESPA2 and SWC5 membranes (Figure 2). The large standard deviations in the contact angle of the SWC5 membrane indicate that this membrane surface is less homogeneous than the ESPA2. Changes in the membrane hydrophobicity indicate modifications in the membrane surface chemistry or conformation [32]. The decrease in hydrophobicity observed here can be attributed to the dissociation of carboxyl and amine groups which produced hydrophilic [ $\left.\mathrm{COO}^{-}\right]$and $\left[-\mathrm{NH}_{2}\right]$ groups or adsorption of preservative chemicals to the membrane surface. The decrease in hydrophobicity of preserved membranes may result in an increase in the water permeability [33] and a decrease in the fouling propensity of the membrane [34]. In addition, Bernstein et al. [35] reported that a decrease in hydrophobicity would lead to a decrease in boron rejection, although the reason for such observation was not provided.

\section{[Figure 2]}

\subsubsection{Chemical composition}

The impact of chemical preservation on chemical composition of the membrane surface was qualitatively examined by FTIR analysis (Figure 3). In the wavenumber region of $1800-600 \mathrm{~cm}^{-}$

${ }^{1}$, both the polyamide active layer and the polysulfone support layer are sampled due to the penetration depth (>300 nm) of this technique compared to the thickness of the membrane active layer [36]. According to Tang et al. [36], polyamide functional groups are represented at wavenumbers 1663,1609 , and $1541 \mathrm{~cm}^{-1}$, and polysulfone groups are represented at 1587, 1504, 
$1488,1365,1350-1280,1245,1180-1145$, and $830 \mathrm{~cm}^{-1}$. These peaks are clearly observed on Figure 3. The FTIR spectra of the ESPA2 and SWC5 membranes are generally identical, except the appearance of a peak at $1700 \mathrm{~cm}^{-1}$ on the SWC5 which can be assigned to the stretching of $\mathrm{C}=\mathrm{O}$ bonding within either the carbonyl or carboxylic acid groups [37]. It is interesting that this peak lost its intensity as the SWC5 membrane is preserved in formaldehyde $\mathrm{pH} 7$ and SMBS pH 7. The polyamide-represented peaks of the ESPA2 membrane seem not to be affected by the preservative chemicals, however, for the SWC5, some changes are clearly observed at the region $1560-1541 \mathrm{~cm}^{-1}$ (Figure 3). The spectra of the SWC5 samples preserved in formaldehyde $\mathrm{pH} 3$, SMBS pH 3 and DBNPA pH 7 show an additional peak at $1560 \mathrm{~cm}^{-1}$ which is not seen at the virgin SWC5 and those preserved in formaldehyde $\mathrm{pH} 7$ and SMBS pH 7 (Figure 3). The presence of this peak $\left(1560 \mathrm{~cm}^{-1}\right)$ is hardly reported in the literature, and was assigned to the amorphous phase of an unassociated amide [38]. There seems to be a hydrolysis of the amide groups in the membrane active layer under the effects of formaldehyde $\mathrm{pH} 3$, SMBS pH 3 and DBNPA pH 7 solutions. For both virgin and preserved ESPA2 and SWC5 membranes, peaks assigned to polysulfone groups were not affected by preserving chemicals (Figure 3).

\section{[Figure 3]}

\subsection{The rejection of boron and sodium by virgin $R O$ membranes}

The rejections of boron, sodium, and conductivity by the ESPA2 and SWC5 membranes were determined as a function of permeate flux, temperature, and solution $\mathrm{pH}$ to establish the referencing baseline for subsequent evaluation of the impact of chemical preservation. As expected, sodium and conductivity rejections by the ESPA2 and SWC5 were high (Figure 4). As a result, the effects of these operating conditions on sodium and conductivity rejection were negligible (Figure 4). In good agreement with the literature [39, 40], boron rejection was strongly affected by flux, temperature and feed solution $\mathrm{pH}$. The increase in permeate flux from 10 to 60 LMH led to an increase in boron rejection by the ESPA2 membrane from 30 to $72 \%$ (Figure 4). Likewise, the increase in water temperature from 10 to $40{ }^{\circ} \mathrm{C}$ resulted in a decrease in boron rejection by the ESPA2 membrane from 67 to 17\%. Similar results were observed with the SWC5 membrane, although the changes in boron rejection were considerably smaller compared to the ESPA2. Boron rejections were comparable at $\mathrm{pH} 7$ and 8 , rapidly increased at $\mathrm{pH}>8$ and approached sodium rejection at $\mathrm{pH} 11$. 


\section{[Figure 4]}

The effects of flux, temperature and $\mathrm{pH}$ on boron and sodium rejection have been previously discussed in the literature. According to the irreversible thermodynamic model, as the permeate flux increases, convective transport of water through the membrane increases while diffusive transport of boron remains constant, resulting in a lower boron concentration in the permeate or a higher boron rejection [18]. The effect of temperature on boron rejection could be attributed to the expansion of the membrane structure and the increase in boron permeability as the solution temperature increases [41]. Boron rejection is governed by steric hindrance mechanism at $\mathrm{pH}<$ $9.2\left(\mathrm{pK}_{\mathrm{a}}\right.$ of boric acid), and by both steric hindrance and charged repulsion at $\mathrm{pH}>9.2$ [22]. The speciation transformation from $\mathrm{B}(\mathrm{OH})_{3}$ to $\mathrm{B}(\mathrm{OH})_{4}{ }^{-}$throughout this $\mathrm{pH}$ value explains the increase in boron rejection as the $\mathrm{pH}$ increased. On the other hand, being a hydrated and charged species at all $\mathrm{pH}$ values, sodium ion can be efficiently removed by $\mathrm{RO}$ membrane regardless of operating condition changes [22]. It is therefore suggested that to maintain the rejection efficiency of the membrane, a proper preservation condition should not cause the risk of membrane swelling and not decrease the surface charged density of the membrane. The former would sustain the efficiency of the size-exclusion mechanism, and the latter facilitates the charged repulsion rejection mechanism.

\subsection{Changes in membrane performance}

As can be seen in Figure 5, small variations in water permeability as well as boron and sodium rejection were observed with the blank experiment (in which the membrane was submerged in pH 7 solution without any preservative chemicals for 14 days). These variations can be used as the baseline for assessing the impact of chemical preservation on water permeability and separation efficiency.

The impacts of chemical preservation on water permeability and separation efficiency of both ESPA2 and SWC5 are dependent on the solution $\mathrm{pH}$ and the preservative itself. At $\mathrm{pH} 7$, chemical preservation using DBNPA led to a severe impact on the membrane separation

efficiency. On the other hand, the impacts caused by formaldehyde and SMBS solution at $\mathrm{pH} 7$ on the rejection of boron and sodium was small and was comparable to that of the blank experiment (Figure 5). When the $\mathrm{pH}$ of the SMBS and formaldehyde solutions was reduced to 3, the impacts of chemical preservation on both boron and sodium rejections were significant. For 
the SWC5 membrane, the decrease in rejections of the samples preserved in formaldehyde $\mathrm{pH} 3$, SMBS pH 3 and DBNPA pH 7 solutions is consistent with the hydrolysis of these membrane surfaces as observed for the FTIR spectra (Figure 3). Nevertheless, for the ESPA2, the loss of performance is not reflected for the FTIR data. It is noteworthy that while the rejection of sodium was less sensitive to the variation in operating conditions than that of boron (Section 3.2), both sodium and boron rejections were strongly impacted by chemical preservation. In addition, the impact of chemical preservation on boron and sodium rejections was more significant than that on the membrane water permeability.

\section{[Figure 5]}

For virgin RO membranes, water permeability is inversely proportional to boron rejection and vice versa $[35,42]$. This phenomenon could be observed with the ESPA2 and SWC5 membranes preserved in formaldehyde solution at $\mathrm{pH} 3$ and 7 and in SMBS solution at $\mathrm{pH} 3$ (Figure 5). Similar results were reported when nanofiltration and RO membranes were exposed to either cleaning or disinfecting agents $[26,43]$. The phenomenon was attributed to the cleavage of polyamide bonding which increased the nominal membrane pore size and so encouraged both water and solute molecules passing through the membrane. In contrast, the DBNPA preservative solution caused a decrease in both water permeability and solute rejection at the same time (Figure 5). The concurrent loss of water permeability and solute rejection was reported elsewhere in the literature [44], and was attributed to the transformation from crystalline regions to an amorphous state. Kang et al. [44] suggested that this transformation led to a cleavage of the polyamide structure which decreased solute rejection, meanwhile created a "soft barrier layer" which was compacted under operating pressure and consequently resulted in a flux decline. This explanation is supported by the FTIR data in Figure 3 which indicate a hydrolysis of the SWC5 membrane polymeric structure under the effect of DBNPA solution.

It is interesting to note that although the ESPA2 and SWC5 membranes were affected at similar magnitude regarding boron and sodium rejections, the water permeability of the SWC5 was more severely impacted than that of the ESPA2. For instance, when preserved in formaldehyde solutions at $\mathrm{pH} 7$ and $\mathrm{pH} 3$ and SMBS solution at $\mathrm{pH}$ 3, water permeability of the SWC5 membrane increased more than $20 \%$, whereas only less than $10 \%$ permeability increase was observed for the ESPA2 membrane (Figure 5). This may probably be attributed to the lower 
contact angle (more hydrophilic) of the preserved SWC5 membranes than that of the ESPA2 membrane as seen in Figure 2.

\section{[Figure 6]}

Of particular note, the impacts of chemical preservation on membrane performance appear to be associated with the redox potential of the preservative solution. The redox potential of the preservative solutions is $\mathrm{pH}$ dependent (Figure 6). In general, the redox potential decreases as the solution $\mathrm{pH}$ increases. At $\mathrm{pH} 3$, the redox potentials of the formaldehyde and SMBS solutions were 186 and $123 \mathrm{mV}$, respectively. At pH 7, the redox potentials of these solutions were -147 and $-38 \mathrm{mV}$, respectively. On the other hand, the DBNPA solution had a high redox potential of $389 \mathrm{mV}$ at $\mathrm{pH}$ 7. Results reported here are consistent with previous studies $[45,46]$ in which an increase in $\mathrm{pH}$ was shown to result in a decrease in the solution redox potential. The strong oxidation potentials of the formaldehyde $\mathrm{pH} 3$, SMBS $\mathrm{pH} 3$ and DBNPA $\mathrm{pH} 7$ solutions also explain the hydrolysis of the SWC5 samples preserved in these solutions. Results from Figures 5 and 6 suggest that a reducing condition is necessary to minimise the impacts of chemical preservation on membrane performance. There are currently no specifications about the redox potential of the preservative solution. In addition, it is advisable that the $\mathrm{pH}$ of SMBS and formaldehyde solutions be maintained at near-neutral rather than the recommended $\mathrm{pH}$ value of above 3 currently specified by membrane manufacturers.

The effects of membrane preservation on boron rejection efficiency were further investigated at different operating conditions (Figure 7 and Figure 8). Boron rejection was selected because it could be strongly affected by operating condition changes (Figure 4). Similar to the results obtained at standard testing fluxes, temperatures, and $\mathrm{pH}$ values (Figure 5), the results obtained at other testing conditions show that preservation in the SMBS solution and formaldehyde solution at $\mathrm{pH} 3$ and DBNPA solution at $\mathrm{pH} 7$ caused the most profound effect on the boron rejection (Figure 7 and Figure 8). This result confirms that the membrane polymeric structure was modified by the preservative chemicals and that this impact is irreversible. At various fluxes, $\mathrm{pH}$ values, and temperatures, comparable changes in boron rejection were observed as consequences of membrane preservation. As a result, boron rejection by the preserved ESPA2 and SWC5 membranes responded to changes in operating conditions in a similar manner to that obtained by the virgin membranes. This result implies that boron rejection by the preserved and 
virgin membranes is governed by the same mechanisms which have been elucidated in Section 3.2. The membranes obtained lower boron rejections because its pores became more open as an impact of the preservative chemicals.

\section{[Figure 7]}

\section{[Figure 8]}

\section{Conclusions}

Results reported here show that chemical preservation of polyamide RO membranes may alter the membrane surface properties (i.e., surface charge and hydrophobicity) and subsequently result in negative impacts on both water permeability and solute rejection. Moreover, the effect of chemical preservation on boron and sodium rejections is comparable and more significant than the impact on the membrane water permeability. The impact of chemical preservation on the membrane performance is dependent on the solution $\mathrm{pH}$ and the preservative itself. The results demonstrate that the undesirable impacts of chemical preservation can be minimised by appropriate selection of the preservatives and by preserving the membrane in a reducing condition. Our results suggest that formaldehyde and sodium metabisulfite may be used as preservative chemicals; however, it is necessary to maintain the preservative solution at nearneutral $\mathrm{pH}$.

\section{References}

[1] Shannon, M.A., P.W. Bohn, M. Elimelech, J.G. Georgiadis, B.J. Marinas, and A.M. Mayes, Science and technology for water purification in the coming decades. Nature, 2008. 452: 301-310.

[2] Elimelech, M. and W.A. Phillip, The future of seawater desalination: Energy, technology, and the environment. Science, 2011. 333: 712-717.

[3] Wintgens, T., T. Melin, A. Schäfer, S. Khan, M. Muston, D. Bixio, and C. Thoeye, The role of membrane processes in municipal wastewater reclamation and reuse. Desalination, 2005. 178: 1-11.

[4] Nair, M. and D. Kumar, Water desalination and challenges: The Middle East perspective: A review. Desalination and Water Treatment, 2013. 51: 2030-2040.

[5] Greenlee, L.F., D.F. Lawler, B.D. Freeman, B. Marrot, and P. Moulin, Reverse osmosis desalination: Water sources, technology, and today's challenges. Water Research, 2009. 43: 2317-2348. 
[6] Fritzmann, C., J. Löwenberg, T. Wintgens, and T. Melin, State-of-the-art of reverse osmosis desalination. Desalination, 2007. 216: 1-76.

[7] Hoang, M., B. Bolto, C. Haskard, O. Barron, S. Gray, and G. Leslie, Desalination in Australia - National Research Flagships, 2009.

[8] El Saliby, I., Y. Okour, H.K. Shon, J. Kandasamy, and I.S. Kim, Desalination plants in Australia, review and facts. Desalination, 2009. 247: 1-14.

[9] Nghiem, L.D., T. Ren, N. Aziz, I. Porter, and G. Regmi, Treatment of coal seam gas produced water for beneficial use in australia: A review of best practices. Desalination and Water Treatment, 2011. 32: 316-323.

[10] Sauvet-Goichon, B., Ashkelon desalination plant - A successful challenge. Desalination, 2007. 203: 75-81.

[11] Harris, C., Modular desalting for specialized applications. Desalination, 2000. 132: 269274.

[12] Altman, S.J., R.P. Jensen, M.A. Cappelle, A.L. Sanchez, R.L. Everett, H.L. Anderson, and L.K. McGrath, Membrane treatment of side-stream cooling tower water for reduction of water usage. Desalination, 2012. 285: 177-183.

[13] Massot, A., M. Mietton-Peuchot, C. Peuchot, and V. Milisic, Nanofiltration and reverse osmosis in winemaking. Desalination, 2008. 231: 283-289.

[14] Schliebs, M., Mothballs at the ready for \$1.8bn desal plant, in The Australian March 27, 2013.

[15] Holloway, M.D., C. Nwaoha, and O.A. Onyewuenyi, eds. Process Plant Equipment Operation, Reliability, and Control. 2012, Wiley.

[16] Majamaa, K., U. Bertheas, F. Finlayson, and R.B. Levy, Preservation of reverse osmosis membranes with non oxidizing biocides - Comparison with SMBS. Water Science \& Technology: Water Supply, 2011. 11: 342-351.

[17] Hydranautics, Biocides for Disinfection and Storage of Hydranautics Membrane Elements, 2013. TSB110.11.

[18] Kezia, K., J. Lee, A.J. Hill, and S.E. Kentish, Convective transport of boron through a brackish water reverse osmosis membrane. Journal of Membrane Science, 2013. 445: 160-169.

[19] Shaffer, D.L., N.Y. Yip, J. Gilron, and M. Elimelech, Seawater desalination for agriculture by integrated forward and reverse osmosis: Improved product water quality for potentially less energy. Journal of Membrane Science, 2012. 415-416: 1-8.

[20] Jin, X., Q. She, X. Ang, and C.Y. Tang, Removal of boron and arsenic by forward osmosis membrane: Influence of membrane orientation and organic fouling. Journal of Membrane Science, 2012. 389: 182-187.

[21] Tu, K.L., L.D. Nghiem, and A.R. Chivas, Boron removal by reverse osmosis membranes in seawater desalination applications. Separation and Purification Technology, 2010. 75: 87-101. 
[22] Tu, K.L., L.D. Nghiem, and A.R. Chivas, Coupling effects of feed solution $\mathrm{pH}$ and ionic strength on the rejection of boron by NF/RO membranes. Chemical Engineering Journal, 2011. 168: 700-706.

[23] Tu, K.L., A.R. Chivas, and L.D. Nghiem, Effects of membrane fouling and scaling on boron rejection by nanofiltration and reverse osmosis membranes. Desalination, 2011. 279: 269-277.

[24] Huertas, E., M. Herzberg, G. Oron, and M. Elimelech, Influence of biofouling on boron removal by nanofiltration and reverse osmosis membranes. Journal of Membrane Science, 2008. 318: 264-270.

[25] Fujioka, T., S.J. Khan, J.A. McDonald, A. Roux, Y. Poussade, J.E. Drewes, and L.D. Nghiem, N-nitrosamine rejection by nanofiltration and reverse osmosis membranes: The importance of membrane characteristics. Desalination, 2013. 316: 67-75.

[26] Do, V.T., C.Y. Tang, M. Reinhard, and J.O. Leckie, Effects of chlorine exposure conditions on physiochemical properties and performance of a polyamide membrane mechanisms and implications. Environmental Science and Technology, 2012. 46: 1318413192.

[27] Simon, A., W.E. Price, and L.D. Nghiem, Influence of formulated chemical cleaning reagents on the surface properties and separation efficiency of nanofiltrationmembranes. Journal of Membrane Science, 2013. 432: 73-82.

[28] Childress, A.E. and M. Elimelech, Effect of solution chemistry on the surface charge of polymeric reverse osmosis and nanofiltration membranes. Journal of Membrane Science, 1996. 119: 253-268.

[29] Elimelech, M., W.H. Chen, and J.J. Waypa, Measuring the zeta (electrokinetic) potential of reverse osmosis membranes by a streaming potential analyzer. Desalination, 1994. 95: 269-286.

[30] Simon, A., L.D. Nghiem, P. Le-Clech, S.J. Khan, and J.E. Drewes, Effects of membrane degradation on the removal of pharmaceutically active compounds (PhACs) by NF/RO filtration processes. Journal of Membrane Science, 2009. 340: 16-25.

[31] Schnitzer, C. and S. Ripperger, Influence of surface roughness on streaming potential method. Chemical Engineering and Technology, 2008. 31: 1696-1700.

[32] Tang, C.Y., Y.-N. Kwon, and J.O. Leckie, Effect of membrane chemistry and coating layer on physiochemical properties of thin film composite polyamide RO and NF membranes: II. Membrane physiochemical properties and their dependence on polyamide and coating layers. Desalination, 2009. 242: 168-182.

[33] Akin, O. and F. Temelli, Probing the hydrophobicity of commercial reverse osmosis membranes produced by interfacial polymerization using contact angle, XPS, FTIR, FESEM and AFM. Desalination, 2011. 278: 387-396.

[34] Li, Q., Z. Xu, and I. Pinnau, Fouling of reverse osmosis membranes by biopolymers in wastewater secondary effluent: Role of membrane surface properties and initial permeate flux. Journal of Membrane Science, 2007. 290: 173-181. 
[35] Bernstein, R., S. Belfer, and V. Freger, Toward improved boron removal in RO by membrane modification: Feasibility and challenges. Environmental Science and Technology, 2011. 45: 3613-3620.

[36] Tang, C.Y., Y.-N. Kwon, and J.O. Leckie, Effect of membrane chemistry and coating layer on physiochemical properties of thin film composite polyamide $\mathrm{RO}$ and $\mathrm{NF}$ membranes: I. FTIR and XPS characterization of polyamide and coating layer chemistry. Desalination, 2009. 242: 149-167.

[37] Pavia, D.L., G.M. Lampman, G.S. Kriz, and J.R. Vyvyan, Introduction to Spectroscopy 2009, Belmont, CA: Brook/Cole, Cengage Learning.

[38] Porubská, M., O. Szöllős, A. Kóňová, I. Janigová, M. Jašková, K. Jomová, and I. Chodák, FTIR spectroscopy study of polyamide-6 irradiated by electron and proton beams. Polymer Degradation and Stability, 2012. 97: 523-531.

[39] Koseoglu, H., N. Kabay, M. Yüksel, S. Sarp, Ö. Arar, and M. Kitis, Boron removal from seawater using high rejection SWRO membranes - impact of $\mathrm{pH}$, feed concentration, pressure, and cross-flow velocity. Desalination, 2008. 227: 253-263.

[40] Hung, P.V.X., S.-H. Cho, and S.-H. Moon, Prediction of boron transport through seawater reverse osmosis membranes using solution-diffusion model. Desalination, 2009. 247: 33-44.

[41] Ben Amar, N., H. Saidani, J. Palmeri, and A. Deratani, Effect of temperature on the rejection of neutral and charged solutes by Desal 5 DK nanofiltration membrane. Desalination, 2009. 246: 294-303.

[42] Tu, K.L., T. Fujioka, S.J. Khan, Y. Poussade, A. Roux, J.E. Drewes, A.R. Chivas, and L.D. Nghiem, Boron as a surrogate for N-nitrosodimethylamine rejection by reverse osmosis membranes in potable water reuse applications. Environmental Science \& Technology, 2013. 47: 6425-6430.

[43] Simon, A., W.E. Price, and L.D. Nghiem, Effects of chemical cleaning on the nanofiltration of pharmaceutically active compounds (PhACs). Separation and Purification Technology, 2012. 88: 208-215.

[44] Kang, G.-D., C.-J. Gao, W.-D. Chen, X.-M. Jie, Y.-M. Cao, and Q. Yuan, Study on hypochlorite degradation of aromatic polyamide reverse osmosis membrane. Journal of Membrane Science, 2007. 300: 165-171.

[45] Das, D.K. and O.K. Medhi, Effect of surfactant and $\mathrm{pH}$ on the redox potential of microperoxidase 11 in aqueous micellar solutions. Journal of the Chemical Society Dalton Transactions, 1998: 1693-1698.

[46] Mayhew, S.G., The effects of $\mathrm{pH}$ and semiquinone formation on the oxidation-reduction potentials of flavin mononucleotide. A reappraisal. European Journal of Biochemistry, 1999. 265: 698-702. 


\section{FIGURE CAPTIONS}

Figure 1: Zeta potential of virgin and preserved ESPA2 and SWC5 membranes. Measurements conducted at room temperature (ca. $25{ }^{\circ} \mathrm{C}$ ) in a $1 \mathrm{mM} \mathrm{KCl}$ solution. Abbreviations: S7 for SMBS at $\mathrm{pH}$ 7, S3 for SMBS at $\mathrm{pH}$ 3, F7 for formaldehyde at $\mathrm{pH}$ 7, F3 for formaldehyde at $\mathrm{pH}$ 3, D7 for DBNPA at $\mathrm{pH} 7$.

Figure 2: Contact angle values of virgin and preserved ESPA2 and SWC5 membranes. Measurements conducted at room temperature (approximately $25^{\circ} \mathrm{C}$ ), Milli-Q water used as reference solvent. The error bars show the standard deviation of five replicate measurements. Abbreviations: S7 for SMBS at pH 7, S3 for SMBS at pH 3, F7 for formaldehyde at pH 7, F3 for formaldehyde at $\mathrm{pH}$ 3, D7 for DBNPA at $\mathrm{pH} 7$.

Figure 3: ATR-FTIR absorption spectra of virgin and preserved ESPA2 and SWC5 membranes obtained at $2 \mathrm{~cm}^{-1}$ resolution. Abbreviation: F3 for formaldehyde at $\mathrm{pH} \mathrm{3,} \mathrm{F7} \mathrm{for}$ formaldehyde at $\mathrm{pH}$ 7, S3 for SMBS at pH 3, S7 for SMBS at pH 7, D7 for DBNPA at pH 7.

Figure 4: The rejection of boron, sodium and conductivity by the virgin ESPA2 and SWC5 membranes at various operating conditions. Unless otherwise stated, the testing conditions are: $\mathrm{pH}$ 8, feedwater contains $0.43 \mathrm{mM} \mathrm{B}(\mathrm{OH})_{3}, 10 \mathrm{mM} \mathrm{NaCl}, 1 \mathrm{mM} \mathrm{NaHCO}$, and $1 \mathrm{mM}$ $\mathrm{CaCl}_{2}$; temperature $20^{\circ} \mathrm{C}$, permeate flux $20 \mathrm{LMH}$, cross-flow velocity $42 \mathrm{~cm} . \mathrm{s}^{-1}$. The error bars indicate the standard deviation of seven replicate experiments.

Figure 5: Relative change in pure-water permeability and rejection of boron and sodium by ESPA2 and SWC5 membranes after exposure to preservatives. Standard test conditions: $\mathrm{pH}$ 8, feedwater contains $0.43 \mathrm{mM} \mathrm{B}(\mathrm{OH})_{3}, 10 \mathrm{mM} \mathrm{NaCl}, 1 \mathrm{mM} \mathrm{NaHCO}{ }_{3}$, and $1 \mathrm{mM} \mathrm{CaCl}_{2}$; temperature $20{ }^{\circ} \mathrm{C}$, permeate flux $20 \mathrm{LMH}$, cross-flow velocity $42 \mathrm{~cm} . \mathrm{s}^{-1}$. The error bars show the standard deviation of two replicate experiments. Abbreviations: S7 for SMBS at $\mathrm{pH}$ 7, S3 for SMBS at $\mathrm{pH}$ 3, F7 for formaldehyde at $\mathrm{pH}$ 7, F3 for formaldehyde at $\mathrm{pH}$ 3, D7 for DBNPA at $\mathrm{pH} 7$.

Figure 6: Redox potential of the preserving solutions. Abbreviations: S7 for SMBS at pH 7, S3 for SMBS at $\mathrm{pH}$ 3, F7 for formaldehyde at $\mathrm{pH}$ 7, F3 for formaldehyde at $\mathrm{pH}$ 3, D7 for DBNPA at $\mathrm{pH} 7$.

Figure 7: Relative change in boron rejection by the ESPA2 membrane at different testing fluxes, temperatures, and $\mathrm{pH}$ values. Standard test conditions: $\mathrm{pH}$ 8, feedwater contains 0.43 $\mathrm{mM} \mathrm{B}(\mathrm{OH})_{3}, 10 \mathrm{mM} \mathrm{NaCl}, 1 \mathrm{mM} \mathrm{NaHCO}{ }_{3}$, and $1 \mathrm{mM} \mathrm{CaCl}_{2}$; temperature $20{ }^{\circ} \mathrm{C}$, permeate 
flux $20 \mathrm{LMH}$, cross-flow velocity $42 \mathrm{~cm} . \mathrm{s}^{-1}$. The error bars show the standard deviation of two replicate experiments. Abbreviations: S7 for SMBS at pH 7, S3 for SMBS at pH 3, F7 for formaldehyde at $\mathrm{pH}$ 7, F3 for formaldehyde at $\mathrm{pH}$ 3, D7 for DBNPA at $\mathrm{pH} 7$.

Figure 8: Relative change in boron rejection by the SWC5 membrane at different testing fluxes, temperatures, and $\mathrm{pH}$ values. Standard test conditions: $\mathrm{pH}$ 8, feedwater contains 0.43 $\mathrm{mM} \mathrm{B}(\mathrm{OH})_{3}, 10 \mathrm{mM} \mathrm{NaCl}, 1 \mathrm{mM} \mathrm{NaHCO}_{3}$, and $1 \mathrm{mM} \mathrm{CaCl}_{2}$; temperature $20{ }^{\circ} \mathrm{C}$, permeate flux $20 \mathrm{LMH}$, cross-flow velocity $42 \mathrm{~cm} . \mathrm{s}^{-1}$. The error bars show the standard deviation of two replicate experiments. Abbreviations: S7 for SMBS at pH 7, S3 for SMBS at pH 3, F7 for formaldehyde at $\mathrm{pH}$ 7, F3 for formaldehyde at $\mathrm{pH}$ 3, D7 for DBNPA at pH 7. 

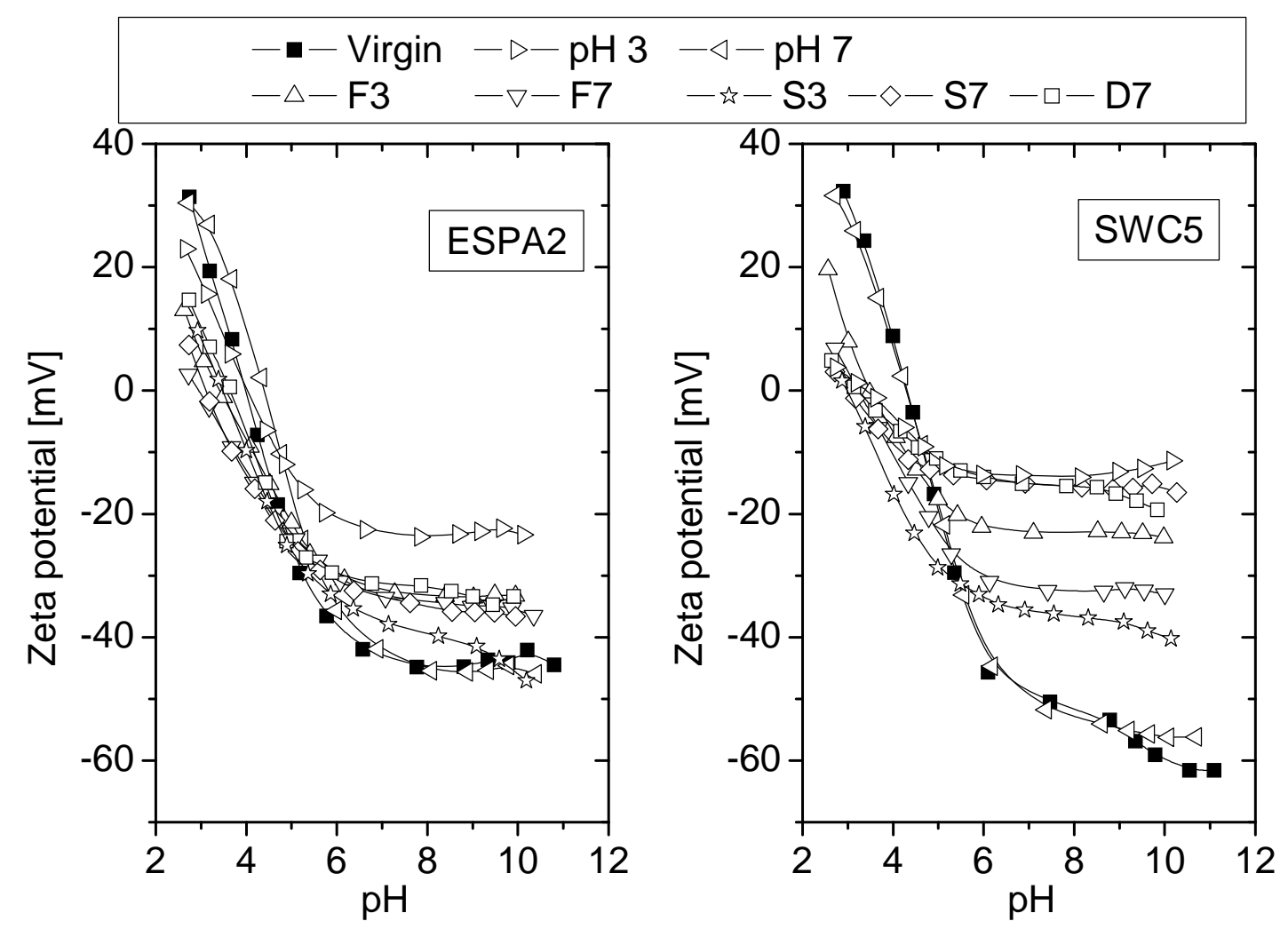

Figure 1

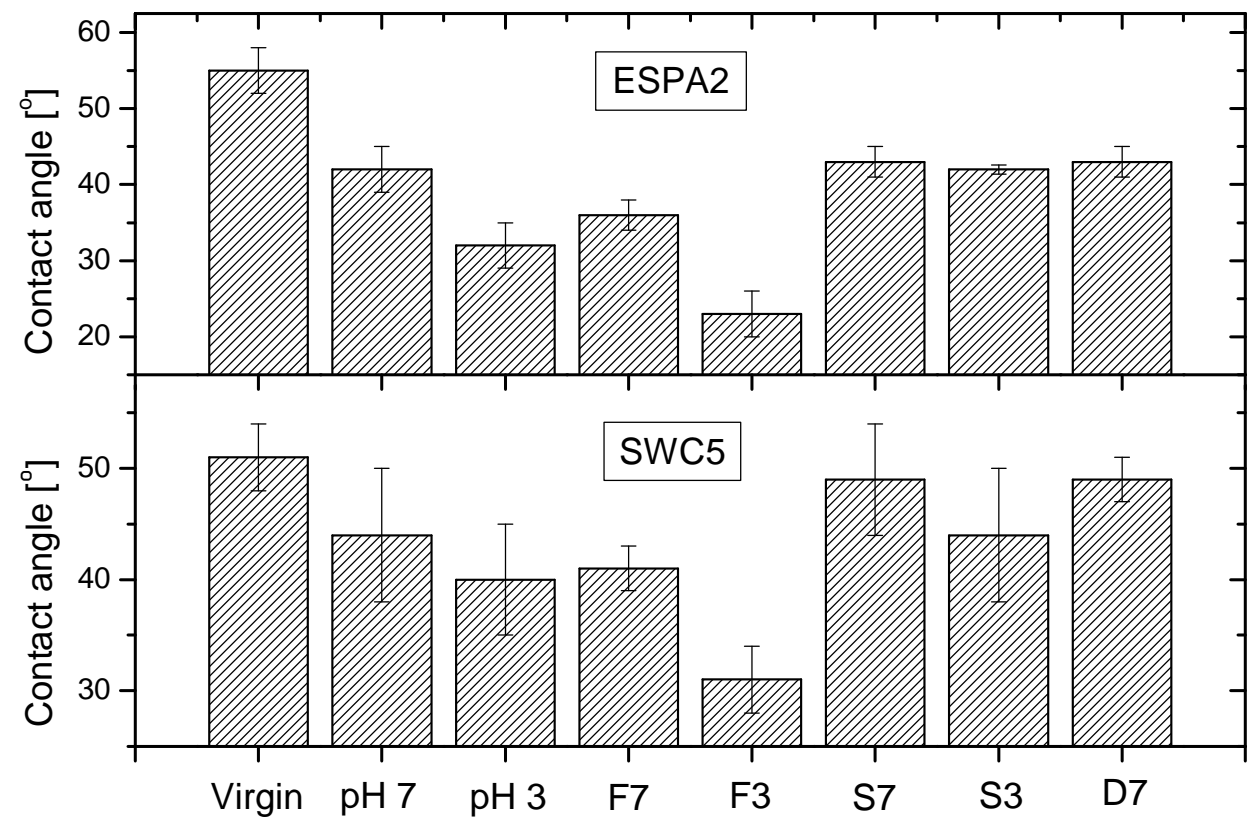

Figure 2 


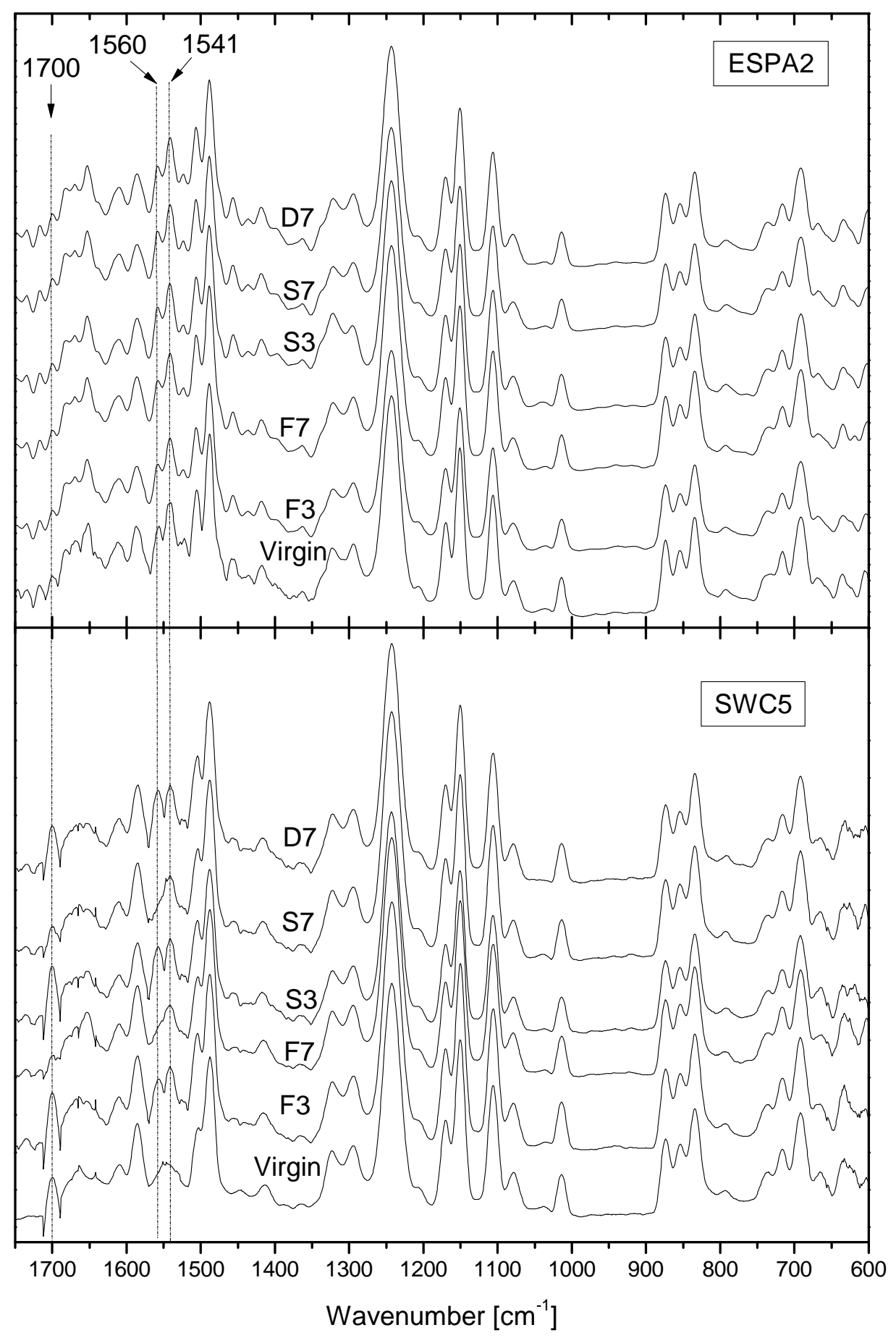

Figure 3 


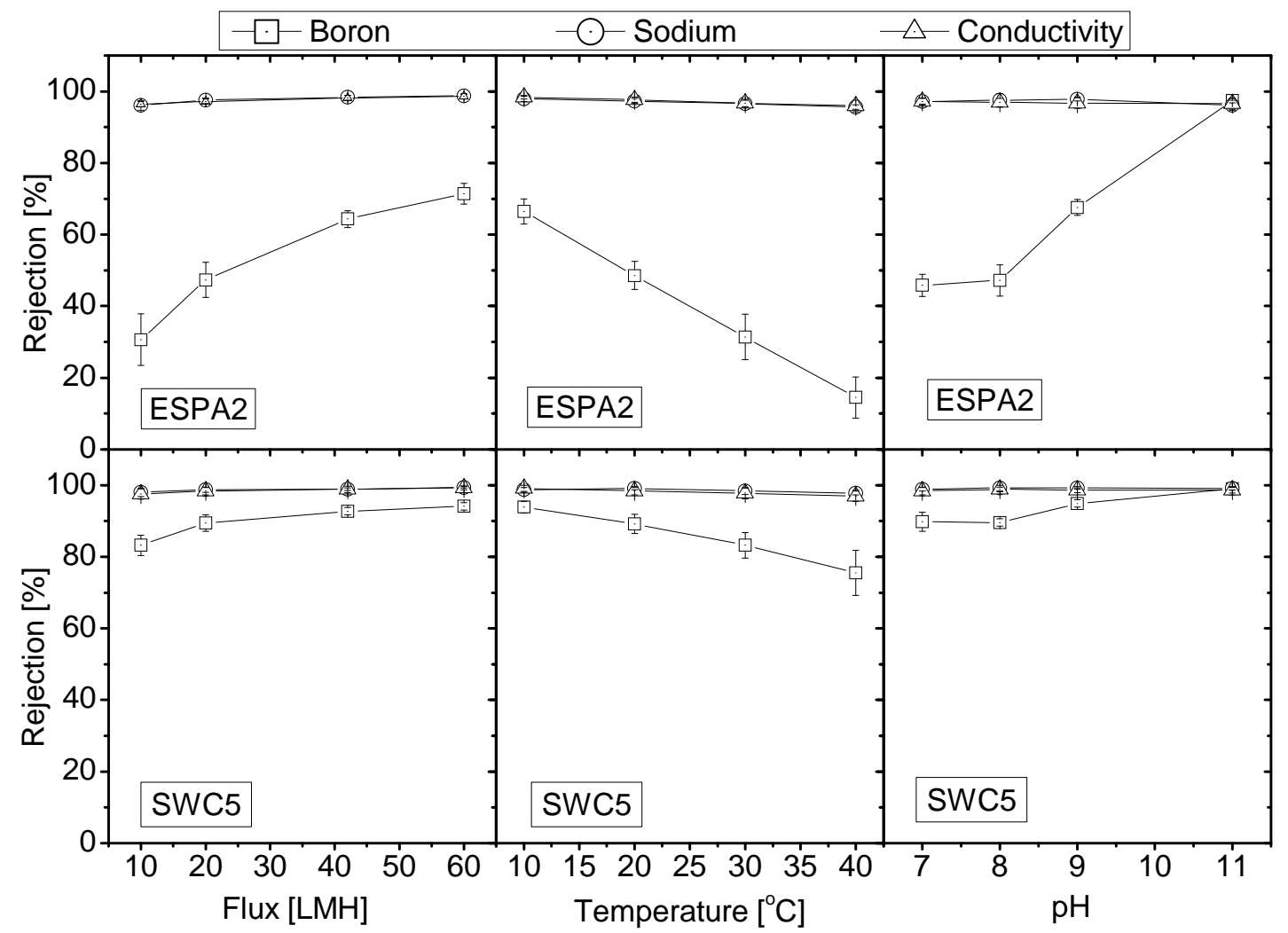

Figure 4

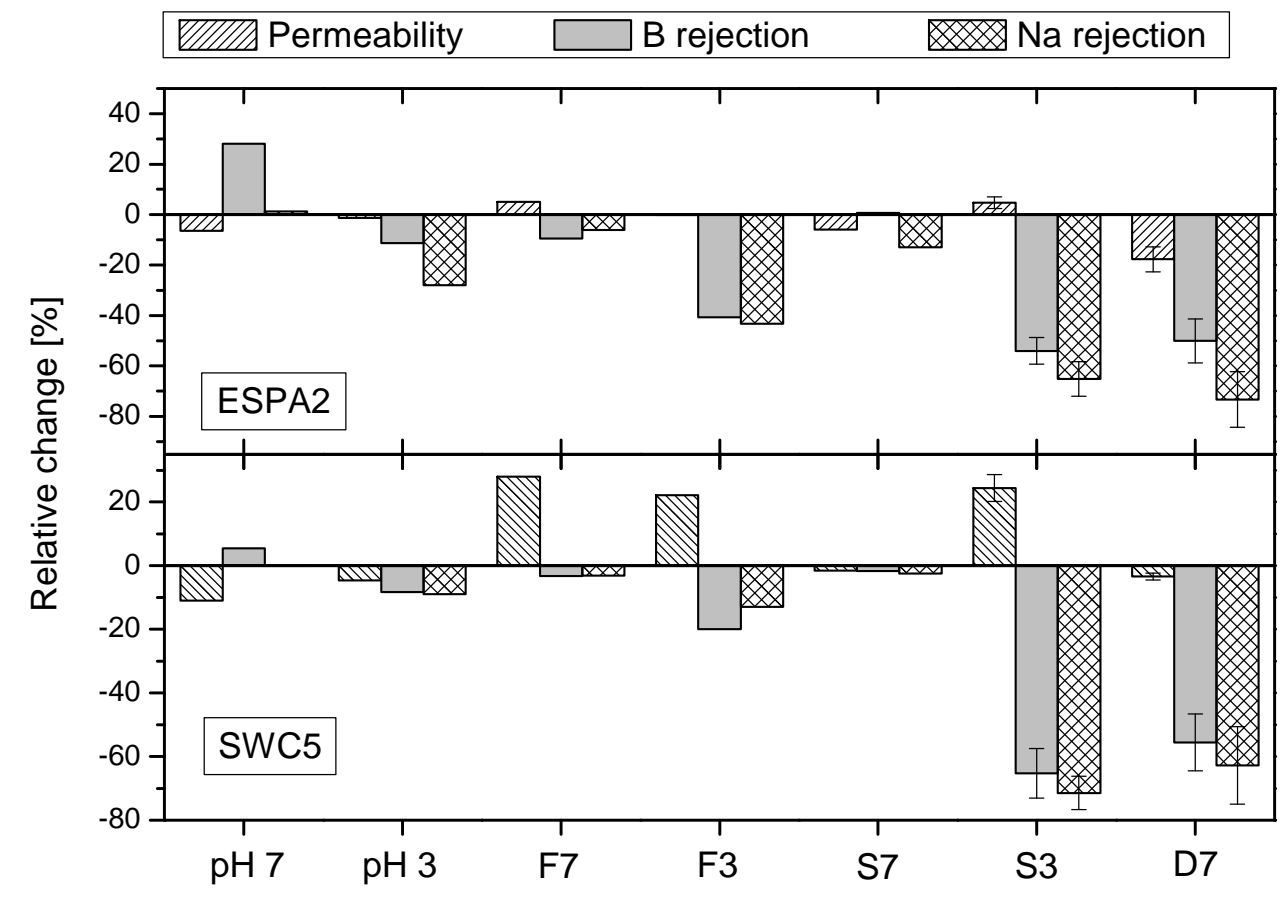

Figure 5 


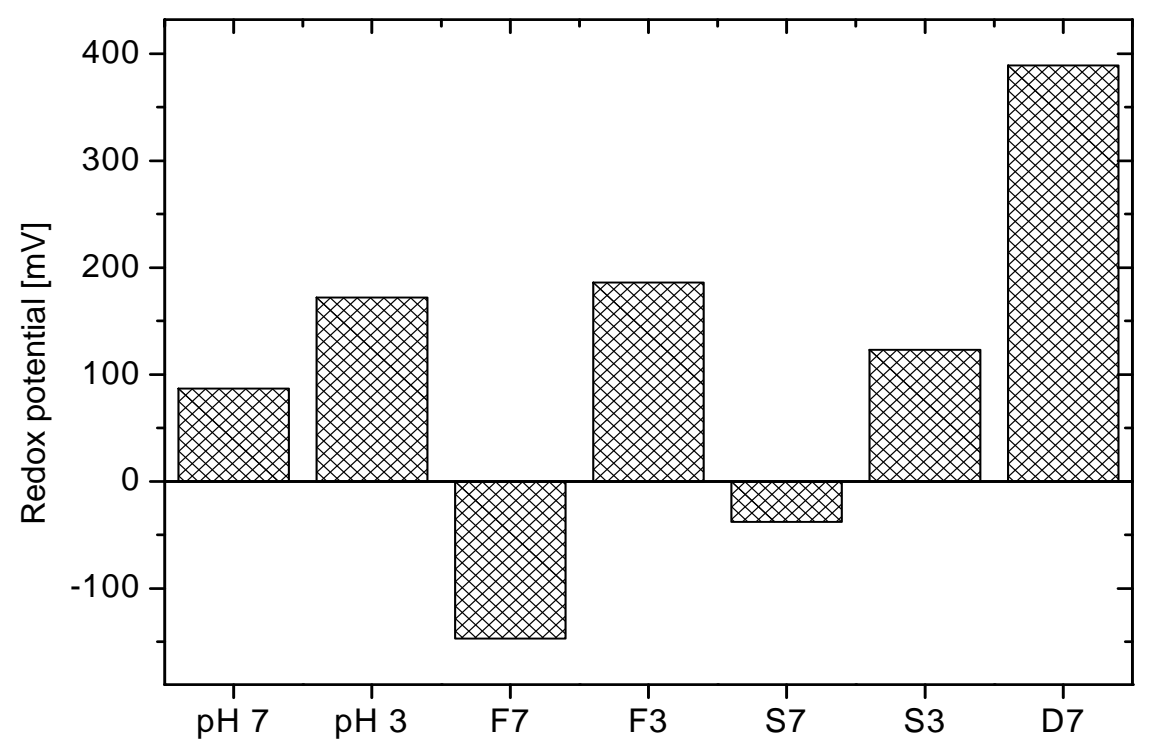

Figure 6

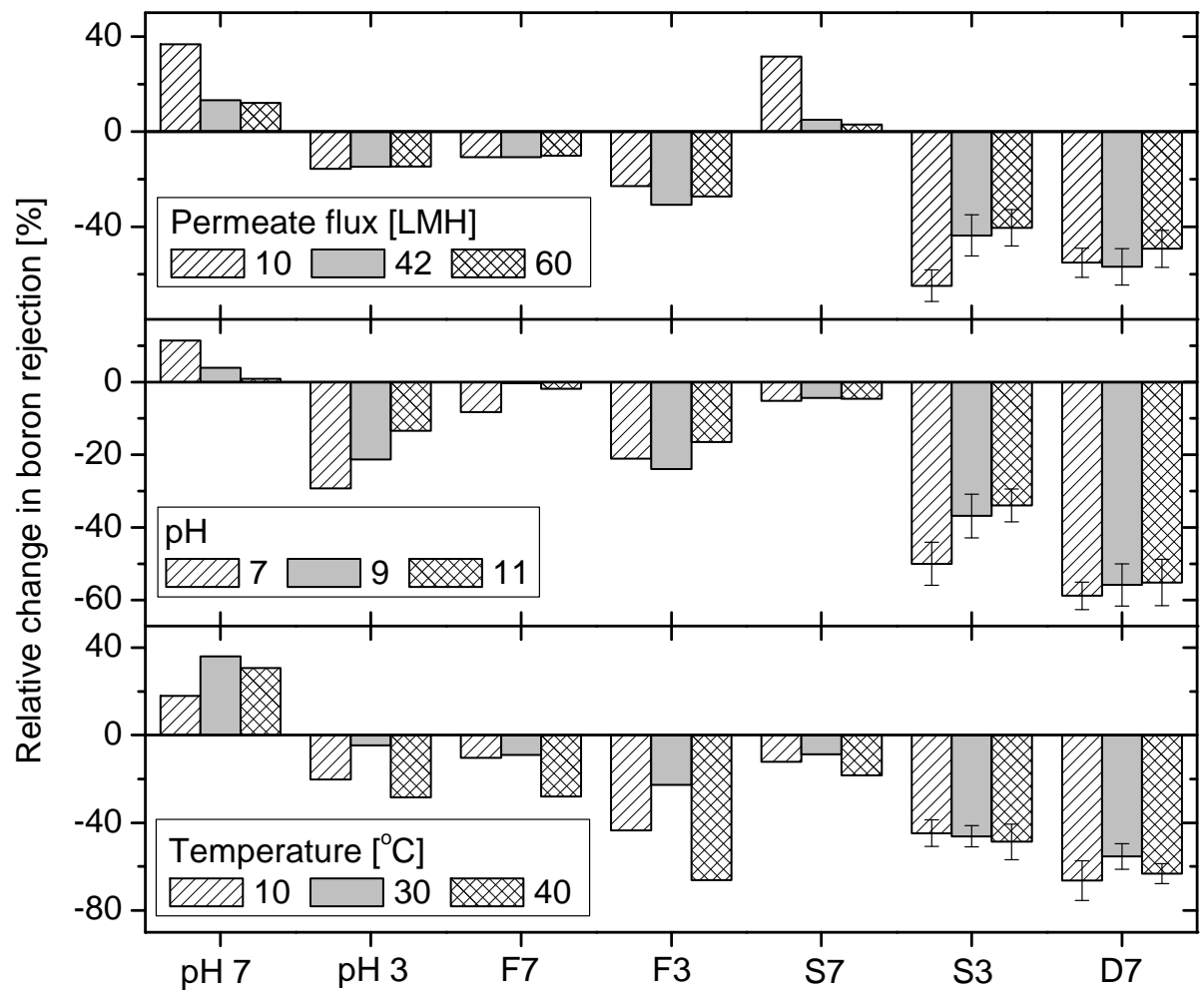

Figure 7 


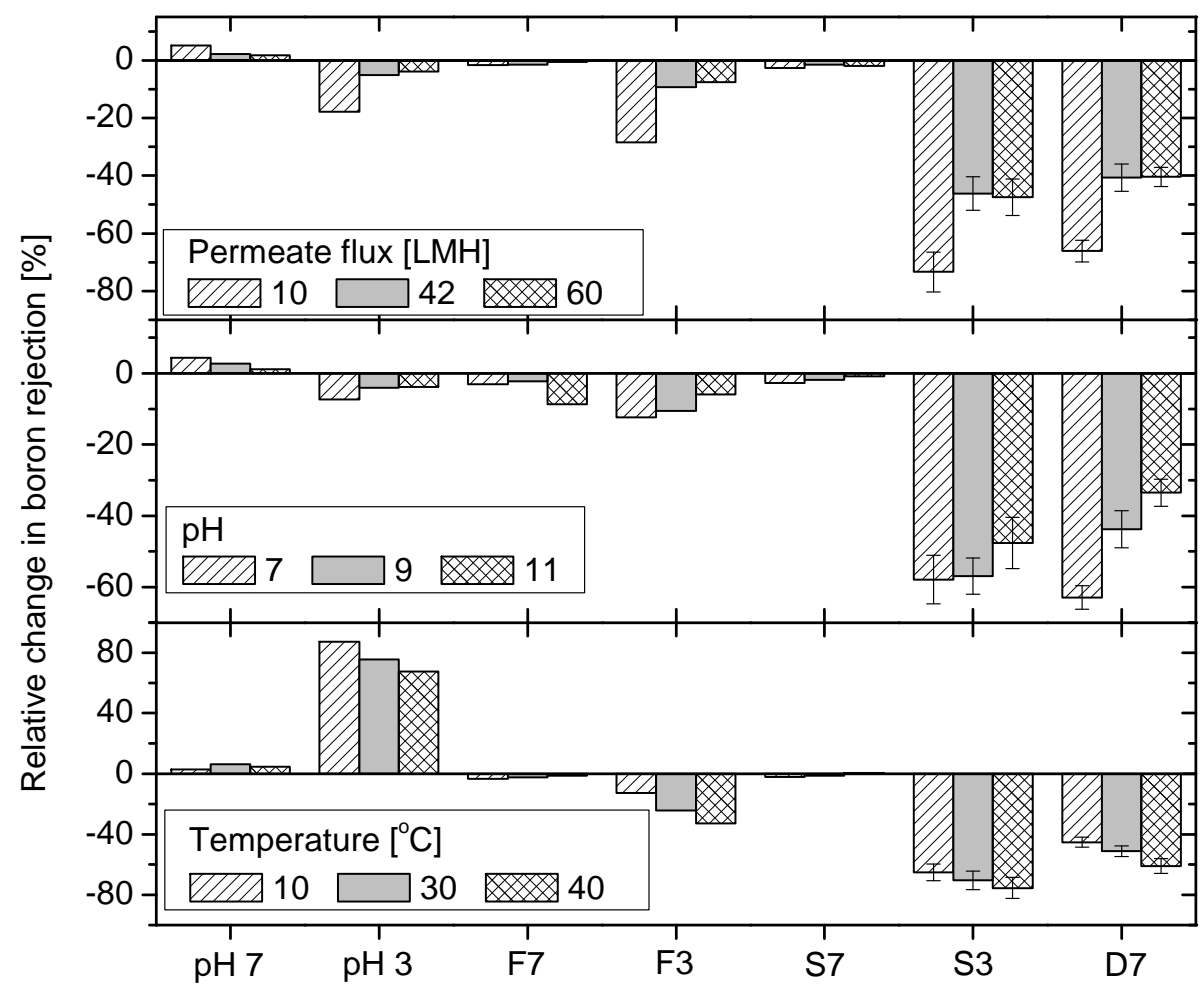

Figure 8 


\title{
Effects of chemical preservation on flux and solute rejection by reverse osmosis membranes
}

\author{
Supplementary Materials \\ Journal of Membrane Science \\ July 2014 \\ Kha L. Tu ${ }^{1}$, Allan R. Chivas ${ }^{2}$, Long D. Nghiem ${ }^{1, *}$ \\ ${ }^{1}$ Strategic Water Infrastructure Laboratory and GeoQuEST Research Centre, School of Civil, \\ Mining and Environmental Engineering \\ University of Wollongong, NSW 2522, Australia \\ ${ }^{2}$ GeoQuEST Research Centre, School of Earth and Environmental Sciences, \\ University of Wollongong, NSW 2522, Australia
}




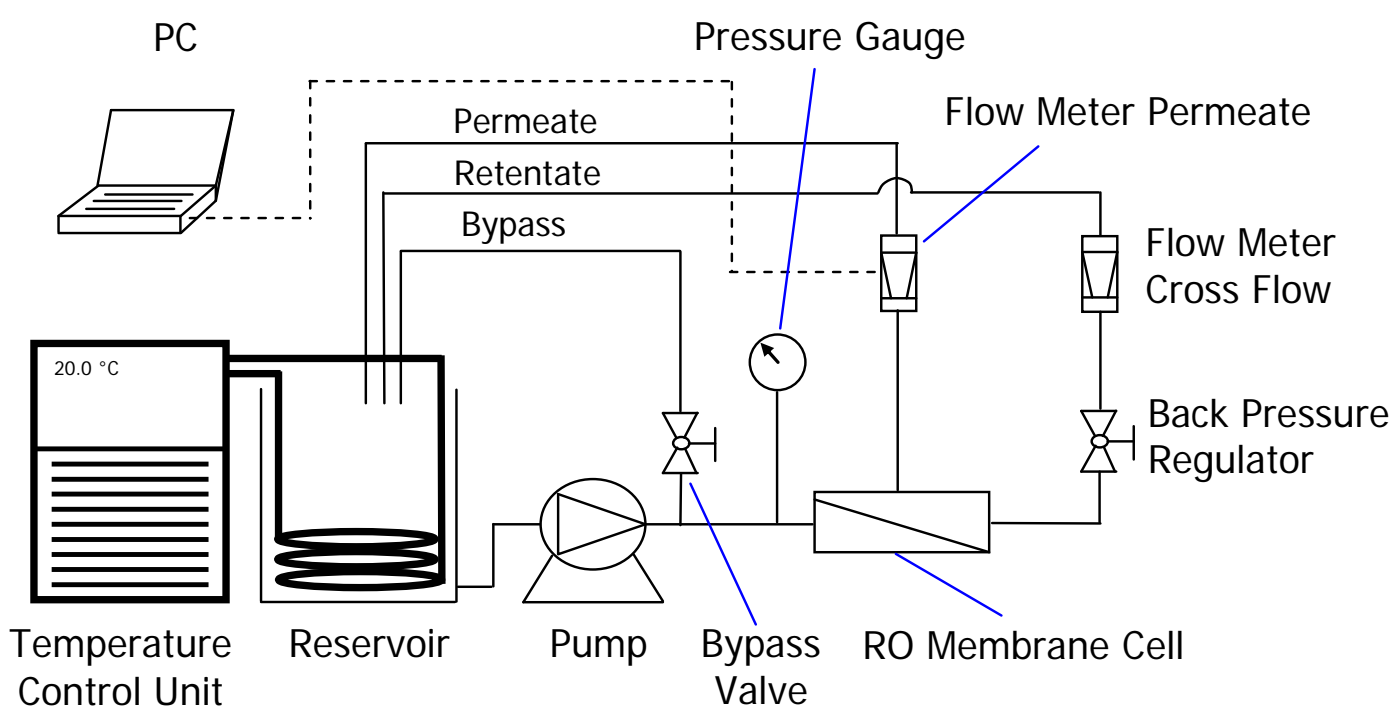

Figure S1: Schematic diagram of the bench-scale cross-flow NF/RO filtration system. 


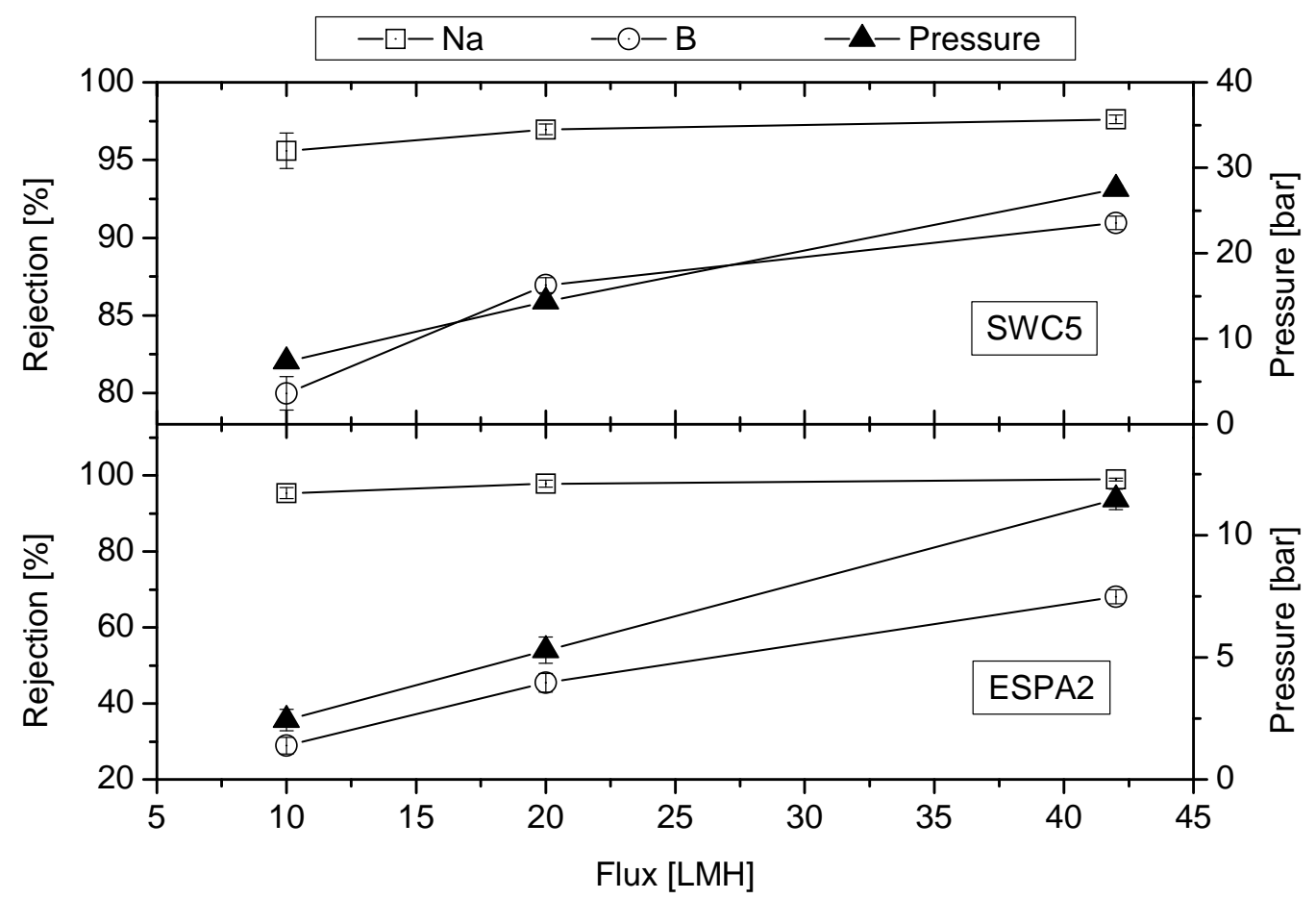

Figure S2: Standard deviation of the rejections and permeability of the ESPA2 and SWC5 membranes as results of three sequences of membrane re-assembling to the filtration cell. The testing conditions are: $\mathrm{pH}$ 8, temperature $20^{\circ} \mathrm{C}$, cross-flow velocity $42 \mathrm{~cm} . \mathrm{s}^{-1}$. Feedwater contains $0.43 \mathrm{mM}(\mathrm{BOH})_{3}, 10 \mathrm{mM} \mathrm{NaCl}, 1 \mathrm{mM} \mathrm{NaHCO}$, and $1 \mathrm{mM} \mathrm{CaCl}_{2}$. 


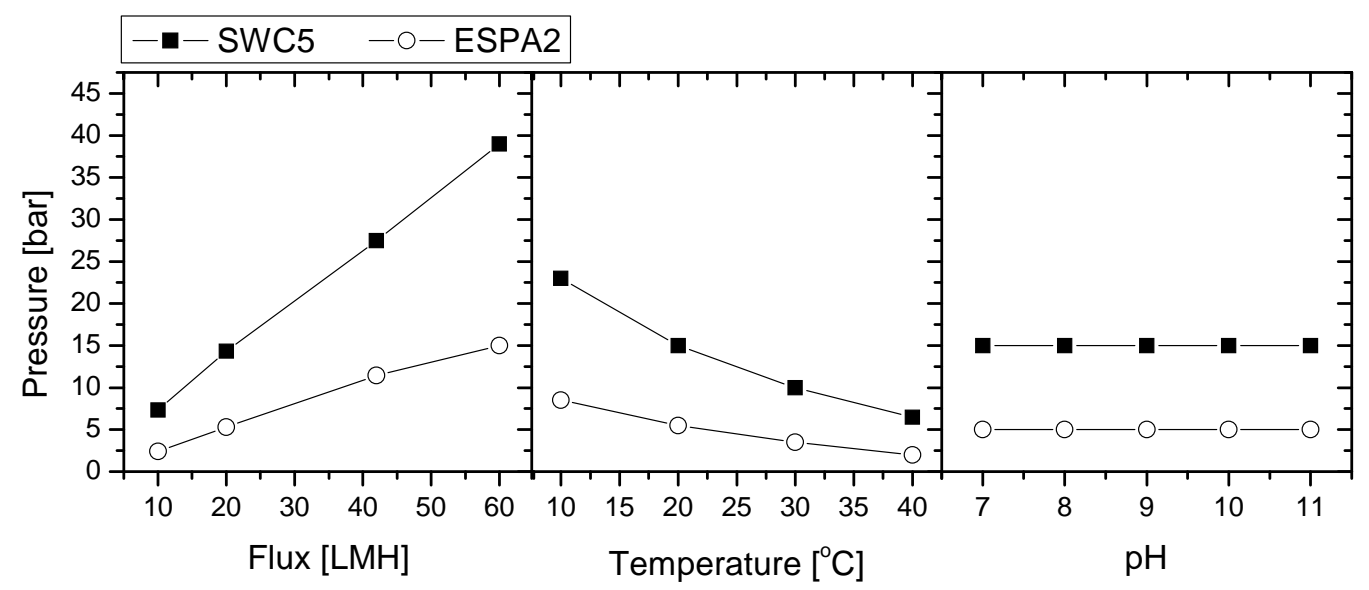

Figure S3: Applied pressure as a function of various operating fluxes, temperatures and feedwater $\mathrm{pH}$ values. The SWC5 and ESPA2 membranes were used. Unless otherwise stated, the testing conditions are: $\mathrm{pH}$ 8, temperature $20{ }^{\circ} \mathrm{C}$, permeate flux $20 \mathrm{LMH}$, cross-flow velocity $42 \mathrm{~cm}^{-1}{ }^{-1}$. Feedwater contains $0.43 \mathrm{mM}(\mathrm{BOH})_{3}, 10 \mathrm{mM} \mathrm{NaCl}, 1 \mathrm{mM} \mathrm{NaHCO}$, and $1 \mathrm{mM} \mathrm{CaCl}_{2}$. 